\title{
SIMS2017 The impact of the weather data file on the energy performance certificate, the case of Norway
}

\author{
Alex Gonzalez Caceres ${ }^{1} \quad$ Dimitrios G. Zenginis ${ }^{2} \quad$ Tor Arvid Vik $^{1}$ \\ ${ }^{1}$ Department of Civil Engineering and Energy Technology, OsloMet - Oslo Metropolitan University, Norway, \\ alexgc@oslomet.no \\ ${ }^{2}$ Department of Civil Engineering, Aristotle University of Thessaloniki, Greece
}

\begin{abstract}
Energy Performance Building Directive (EPBD) ask the Member of States to develop a mandatory energy labelling scheme for new and existing buildings, which should include a label rating of the energy efficiency of the building and a list of recommended energy saving measures. The label will provide prospective buyers and tenants of a building with correct information about the energy performance of the building to compare with other options. However, some countries use only one or a limited number of weather zones. In a country like Norway, with significant variations in weather conditions between locations, this is likely to cause a deviation when comparing with the reality. This study aims to present the implication of using only one weather zone in Norway. The method used is based on the comparison of three types of weather files. The first one is used in the labelling system, which is a typical year, while the others are typical reference years from the local site from different providers. The results show significant differences in energy consumption, savings and labelling ratings when applying files with local weather data instead of the official weather data file used in Norway.
\end{abstract}

Keywords: certificate, energy labelling, IWEC, weather file, reference year, EPC

\section{Introduction}

The Energy Performance Building Directive (2010/31/EU) requires the Member States to lay down the necessary measures to establish a system of certification of the energy performance of buildings, including a methodology for the calculation of the energy performance of buildings. The building energy certification and rating system is an essential method for improving energy efficiency, minimizing energy consumption and enabling greater transparency regarding energy use in buildings. Basically, in a building energy rating scheme, a standardized method to evaluate and compare energy use, energy efficiency and energy cost in buildings, is provided (Institute for Market Transformation (IMT), 2009). Building rating schemes usually have common purposes. Their implementation and design can have large differences, though, due to local conditions in each country, such as building stock, climate and Landlord-Tenant legislation (International Energy Agency (IEA), 2010).

The final goal of building energy rating schemes is to reduce energy consumption in the building sector. In order to do so it has to be accompanied by other policy packages, since the labelling does not improve the energy efficiency itself. Instead, the energy labelling allow to assess the efficacy of policies, and to improve and design complementary instruments to achieve energy reduction in buildings (Tasktroup, 2014; Hinge, Neely, \& Taylor, 2014). In order to obtain positive results through the system of policies for energy reduction in buildings, tools like energy labelling should provide robust data. Stakeholders must be confident that the analysis can predict relevant metrics such as energy use and energy savings accurately (Polly, Kruis, \& Roberts, 2011).

This research focus at the accuracy of the energy labelling tools under the Norwegian scheme. The aspects covered in this study are mainly the impact of the weather data from different sources analysing the energy performance, energy rating and renovation strategies under the Energy Performance Certificate (EPC), with special attention to its variations.

\subsection{Importance of the weather file}

The energy consumption and indoor environment can be determinated by considering the impact of different factors acting in the energy and mass transfer. These factors are weather data, occupant behaviour and auxiliary systems (Hensen, 1999). The parameter of the weather is within the most important factors that impact the energy demand of buildings (Fumo, 2014). Even more, the selected weather data should be considered carefully. Due to this, weather data quality will determine the effectiveness of building design strategies and the accuracy of the energy calculation (Hui \& Cheung, 1997). Thus, the weather file becomes a major component in order to achieve reliable energy savings from energy management practices and retrofits (Fumo, 2014). 
In addition, the weather data is completely out of the control of the person performing an energy labelling calculation (Erba, Causone, \& Armani, 2017). Because of this, decisions related to the design of the labelling tools, should exhaustively include the criteria for selection of weather data.

\subsection{Type of weather files}

Weather data files are used in simulation according to the purposes of the study, and each developer designs their data to meet a particular need (Crawley, 1998). Weather data files are usually generated to represent long-term statistical trends and patterns of the climate for a long period of record.

The weather data file can be generated mainly by two primary sources: measured weather data using physical sensors, and simulated data using mathematical models (Hong, Chang, \& Lin, 2013). The preparation of these weather data files includes many variables, which are not necessarily correlated, and thus represent a great challenge. For energy labelling tools, where the aim is to compare different buildings, a typical weather year file will normally be used. When the aim is to obtain retrofit recommendations, average weather data would be most practical (Fumo, 2014). According to Crawley (Crawley, 1998), typical reference year data should be avoided for energy simulations, since they cannot represent typical long-term weather patterns. Several methods have been proposed to generate annual hourly weather files, also known as reference year, which are the most common for energy simulations. Examples are Typical Meteorological Year (TMY), test reference year (TRY), weather year for energy calculation (WYEC), International Weather for Energy Calculations (IWEC), as well as the design reference year (DRY).

Reference year files are a single year composed of 12 months selected as the most representative in a multiyear series. These files are characterized by having a true frequency, true sequences and true correlations (Lund, 1991; Lund \& Eidorff, 1981), the last one being the most important (Guan, 2009). This means that a reference year has to be prepared starting from actual weather recordings, selecting the most typical ones without altering the cross-correlations among weather variables (Pernigotto, Prada, Cappelletti, \& Gasparella, 2017).

Among the most widespread weather data is the IWEC (Gherri, 2015; Roetzel \& Tsangrassoulis, 2011), which were developed under the American Society of Heating, Refrigerating, and Air-Conditioning Engineers (ASHRAE) research project RP-1015 (Thevenard \& Brunger, 2002). ASHRAE collected hourly raw data worldwide in attempt to unify weather files in a format similar to TMY3 (Herrera et al., 2017). A comprehensive amount of observations are considered, covering from 12 to 25 years of records, including parameters such as wind speed and direction, sky cover, visibility, ceiling height, dry-bulb temperature, dewpoint temperature, atmospheric pressure, liquid precipitation etc. Hourly data for radiation are estimated empirically based on other parameters. Recently, ASHRAE has updated the format into a IWEC2 (Y. J. Huang, 2014), which contain an improved estimation of the solar radiation. Currently there are available 3012 weather files for locations outside USA and Canada (J. Huang, 2010).

Lack of long-term weather records usually limits the generation of typical annual weather data files in any format (Al-Mofeez, Numan, Alshaibani, \& Al-Maziad, 2012). Because of this, it is common for engineers to use synthetic weather data, generated e.g. by the commercial software Meteonorm. This tool includes a database for solar energy applications combined with a synthetic weather data generator. It can produce weather files for any site with a time resolution of an hour or even a minute (Remund, Müller, Schilter, \& Rihm, 2010). Meteornorm integrates a climate database of measurements collected from various sources (8350 weather stations by 2018), which allow to create an average year based on monthly mean values from a long-term dataset.

\subsection{Energy labelling system}

The certificate is required whenever a building is constructed or for existing buildings, before it is marketed for sale or rent. EPCs are produced using standard methods with standard assumptions about energy usage so that the energy efficiency of one building can easily be compared with another building of the same type (Cappelletti, Dalla Mora, Peron, Romagnoni, \& Ruggeri, 2015). EPCs and inspection reports intend to provide accurate and valuable information to building owners and tenants on the energy performance of their buildings. It is also supposed to specify recommendations about how the property can be improved, which will be an important factor to help building owners in a tangible way. According to the IDEAL EPBD project, the trust in the energy performance rating was found to be much higher if specific recommendations on how to improve the energy performance of the building are included in the certificates (Backhaus, Tigchelaar, \& de BestWaldhober, 2011).

Since the EPBD allow some freedom in the implementation of the labelling system, many countries have implemented the EPC system according to the local needs. With this variety of certification schemes, challenges were identified such as how to improve the quality of the results and along with that the recommendations, without increasing the values of the certificates. One of the suggestions is to ensure that recommendations accompanying the EPC relate to actual climate and energy consumption (Geissler \& Altmann, 2015). This is relevant particularly for 
countries like Norway, where only one weather file for the entire country is used in the energy labelling system.

The reason of harmonizing the climate of Norway by using Oslo data could not be found by the authors. However, a study performed under the TRANSES in 2009 states that it can be estimated that about $76 \%$ of dwellings are located in areas with a climate comparable to or milder than the Oslo climate. Hence, the Oslo climate could be adopted as an average climate valid for the entire building stock (Sartori, Wachenfeldt, \& Hestnes, 2009). However, Norway can be classified in seven different climate zones based on the Degree-Days method (Enova, 2006), where large cities can be identified in each zone.

\subsection{Methodology}

The study is presented in three bodies. First, an energylabelling tool is used to estimate the energy demand of the building. The results are used to calibrate a model in EnergyPlus (e+). Second step is to run the e+ model with the weather data sets for the seven climate zones found for Norway, Alta, Bergen, Fagernes, Mo i Rana, Oslo, Trondheim and Tromso. From this, energy consumption and rating are compared. Third step shows how the weather file influences the energy consumption when upgrading the building to passive house level. Three different types of weather data, IWEC, Meteonorm and the standardized Norwegian weather file are applied and their influence on the results is compared. It is noticed that ASHRAE does not have data for zone 5 (Mo i Rana). Due to this, the file from Meteonorm is used, since a comparison between both sources was done, showing similar results with the other cities (Section 2.1).

\subsection{Cases and materials}

The case used for the study is Figure 1 shows the building considered in this investigation. It is conceived as a module of a wooden terraced dwelling from 1994 located in Oslo. The building code from 1987 was the current one at that time.

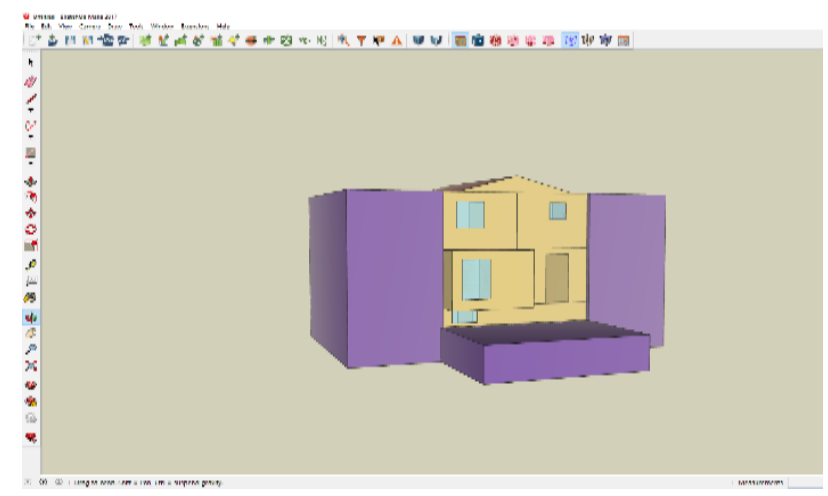

Figure 1. Building model used in the simulations. The model was constructed in Open Studio, and simulated with e+.
The dwelling is $146 \mathrm{~m}^{2}$, distributed on three levels. Some key properties of the dwelling are presented in Table 1 . The U-values are realistic values, ventilation rate is according to NS 3031, while air leakage is the minimum requirement in the 1987 building code.

Table 1. Some key properties of the dwelling.

\begin{tabular}{|c|c|c|}
\hline Component & $\begin{array}{c}\text { Bases } \\
\text { level }\end{array}$ & $\begin{array}{c}\text { Passive house } \\
\text { level }\end{array}$ \\
\hline \multicolumn{3}{|l|}{ U-values $\left[\mathrm{W} /\left(\mathrm{m}^{2} \mathrm{~K}\right)\right.$} \\
\hline External walls & 0.28 & 0.15 \\
\hline Ceiling & 0.32 & 0.10 \\
\hline Expose floors & 0.17 & 0.10 \\
\hline Basement walls & 0.3 & 0.15 \\
\hline Windows/doors & 1.9 & 0.8 \\
\hline Ventilation $\left[\mathrm{m}^{3} / \mathrm{h}\right]$ & 1.2 , exhaust & 1.2 , exhaust \\
\hline Air leakage at $50 \mathrm{~Pa}[\mathrm{ACH}]$ & 4.0 & $2.8^{*}$ \\
\hline
\end{tabular}

*airtightness value does not follow the passive standard since this is a retrofitting case, the air leakage was set according to literature (Gillott et al., 2016).

A second round of simulation were performed after upgrading the initial case to passive house standard (NS 3700). The input data are also presented in Table 1.

The software used for the study is Simien, which is the most common simulation tool for such calculations in Norway. The tool has the Norwegian energy labelling regulation, which is based on NS 3031, integrated. E+ is used to compare the different weather files. The building model, which is shown in Figure 1, is created in Open Studio. According to IBPSA, e+ is the most common building simulation tool worldwide.

\subsection{Weather data analysis}

In order to evaluate the pertinence of the climatic zones proposed by ENOVA, the weather data set (IWEC) for each city are compared based on Heating Degree Days (HDD). Table 2 provides the geo-references of each city, while ENOVA weather classification and HDD are presented in Figure 2. The IWEC weather file contains real weather data, while the Meteonorm data are synthetic. Therefore, the IWEC data are used for this task (except for Mo i Rana as explained above). Figure 2 shows an average difference of 667 HDD between the cities. The minimum difference was 299 HDD between Trondheim and Oslo, while the maximum difference was 3999 HDD between Alta and Bergen. The variations in temperature and solar radiation are presented in Figure 3. The assessment of the weather data shows significant variation in HDD and solar radiation between the selected cities. This reflects that the weather data selected for the assessment are pertinent for the purpose of the study. Since they clearly represent climatic singularities. 
Table 2. Geo-references of the cities

\begin{tabular}{|c|c|c|c|c|}
\hline $\begin{array}{c}\text { Climate } \\
\text { Zone }\end{array}$ & City & Latitude & Longitude & Altitude \\
\hline 1 & Oslo & 59.90 & 10.62 & 17 \\
\hline 2 & Bergen & 60.38 & 5.33 & 36 \\
\hline 3 & Fagernes & 60.98 & 9.23 & 365 \\
\hline 4 & Trondheim & 63.47 & 10.93 & 17 \\
\hline 5 & Mo i Rana & 66.31 & 14.14 & 26 \\
\hline 6 & Tromso & 69.68 & 18.92 & 10 \\
\hline 7 & Alta & 69.98 & 23.37 & 3 \\
\hline
\end{tabular}

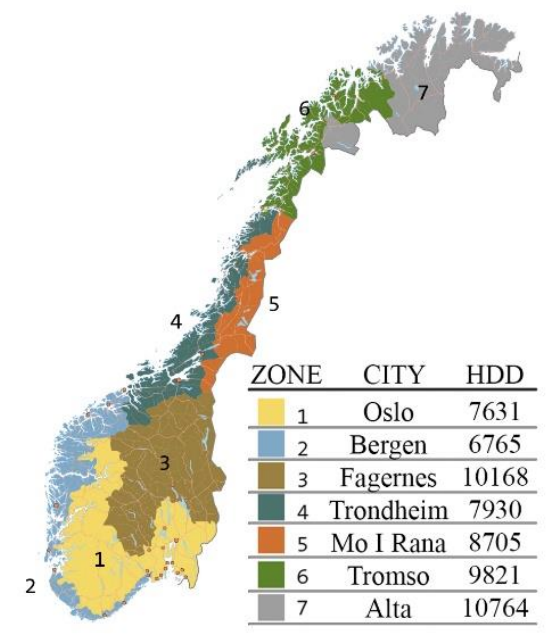

Figure 2. Map of the Climate zones, based on the ENOVA classification, with the HDD from the IWEC file for the selected cities (for Mo i Rana, Meteonorm file was used).

\section{Results}

\subsection{Energy consumption comparisons}

The energy consumption obtained by using IWEC and Meteonorm files is presented in Table 3 and Figure 4. Figure 4 provides the results in case of using the official Norwegian weather data file as well.

Comparing the weather data, an average difference of 3,7\% between IWEC and Meteonorm is observed, while Meteonorm data occurs a lower energy demand for all the cities. Moreover, important differences between the official Norwegian weather file and the other data files, even for zone 1, are also displayed. These differences are attributed to considerable deviations in terms of global solar radiation and dry temperature that exist between the weather files.

Considering IWEC weather data file and taking into account Oslo (zone 1) as a reference, the highest deviation is $60 \mathrm{kWh} / \mathrm{m}^{2}$ per year, represents $31 \%$ increase and is found in Alta (zone 7). Only zone 2, represented by Bergen, shows a lower energy demand than Oslo; $10.5 \mathrm{kWh} / \mathrm{m}^{2}$ less per year, which is a difference of around 7\%. However, the step variation between the zones ranges has an average difference of
7.5 (without considering Mo i Rana). This indicates that the distances in terms of energy consumption between the zones may be too close, however other aspects different than heating needs may be the determinant factor for its differentiation, such as thermal oscillation, solar radiation etc. Moreover, the behaviour per season are notoriously different, which indicate that different strategies might be needed particularly in summer.
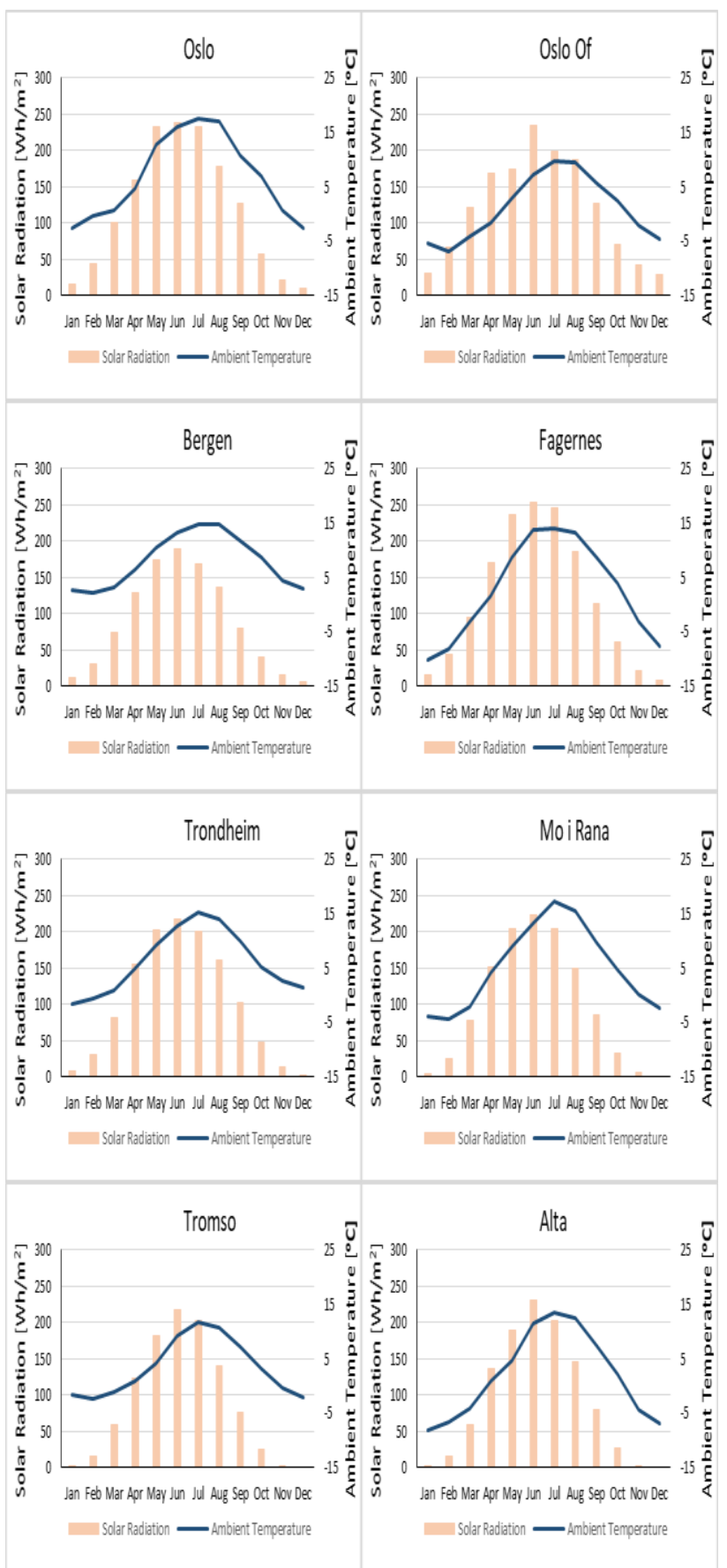

Figure 3. Climate graphs of the cities in the study. The data shows that they are important variations, mainly in temperature and solar radiation, which both have a great impact on the energy demand. 
Table 3. Annual energy consumption for the various climate zones with IWEC and Meteonorm weather data.

\begin{tabular}{|l|c|c|c|}
\hline Climate Zone & IWEC & Meteonorm & Deviation \\
\cline { 2 - 4 } & {$\left[\mathrm{kWh} / \mathrm{m}^{2}\right]$} & {$\left[\mathrm{kWh} / \mathrm{m}^{2}\right]$} & {$[\%]$} \\
\hline 1. Oslo & 149.4 & 136.8 & 8.4 \\
\hline 2. Bergen & 138.9 & 126.5 & 8.9 \\
\hline 3. Fagernes & 185.8 & 180.9 & 2.6 \\
\hline 4. Trondheim & 156.5 & 143.9 & 8.0 \\
\hline 5. Mo i Rana & - & 182.8 & - \\
\hline 6. Tromso & 191.7 & 187.6 & 2.1 \\
\hline 7. Alta & 209.3 & 200.1 & 4.4 \\
\hline Average & 172.0 & 165.6 & 3.7 \\
\hline
\end{tabular}

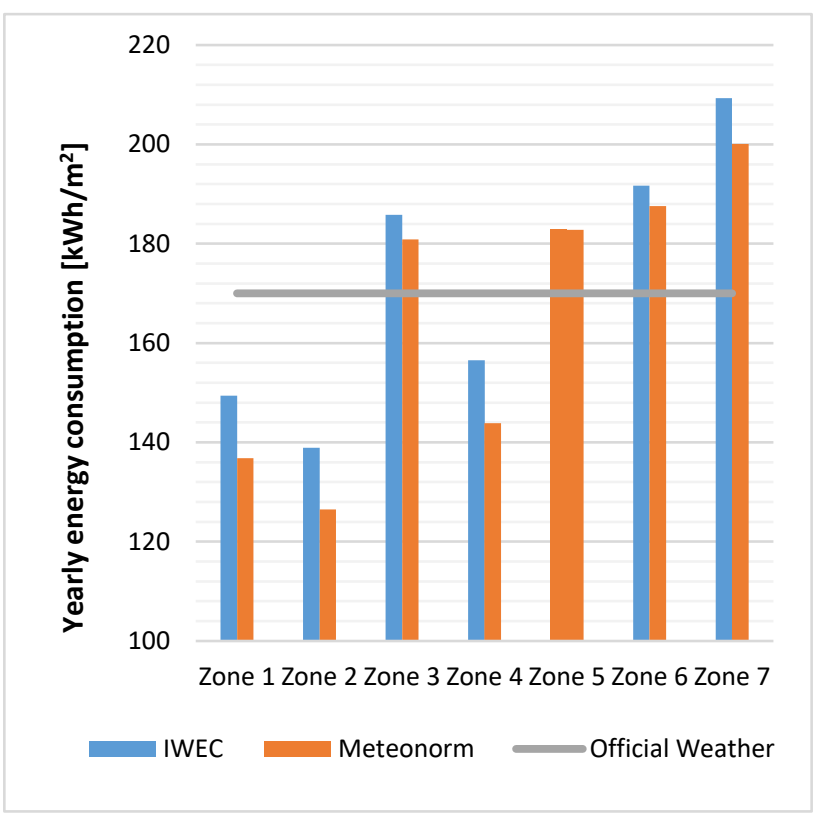

Figure 4. Energy consumption obtained by using the different weather data sources.

\subsection{Monthly analysis}

The results from the simulation with the IWEC database, showed that in terms of heating demands there is not a harmonized map over the different zones. In order to show these differences more clearly, the surface plot in Figure 5 and 6 was designed. The cities are arranged from the highest to the lowest energy demand on one axis, and the same is done with the months on the second axis. The range was set up based on the minimum average differences between the seasons. Thus, four prominent areas cover most of the surface plot. A fifth area (dark blue) with the highest energy demand can be seen for Alta, Fagernes and Mo i Rana. In spite that Tromso has the second highest annual energy demand, it does not reach the dark blue area. This is because the heating demand during summer is much higher than in the other zones. As a reference of the current labelling system in Norway, Oslo was highlighted with a line in red, to easily compare its energy consumption pattern with the rest of the zones. In winter (yellow and dark blue area) Bergen has the shortest period of energy demand, followed by Oslo. The rest of the cities have a common pattern, with a winter behavior period of five months, six for Alta. During the warmest months (Jun-Aug-May) most of the zones have similar heating demands $\left(0\right.$ to $6 \mathrm{kWh} / \mathrm{m}^{2}$ per month, light blue area), except Bergen which has almost five months with low energy demand. Due to low solar radiation, Tromso has no summer period, and Alta has only two months. It could also be noted that Oslo has the most regular distribution of energy demand over all the months.

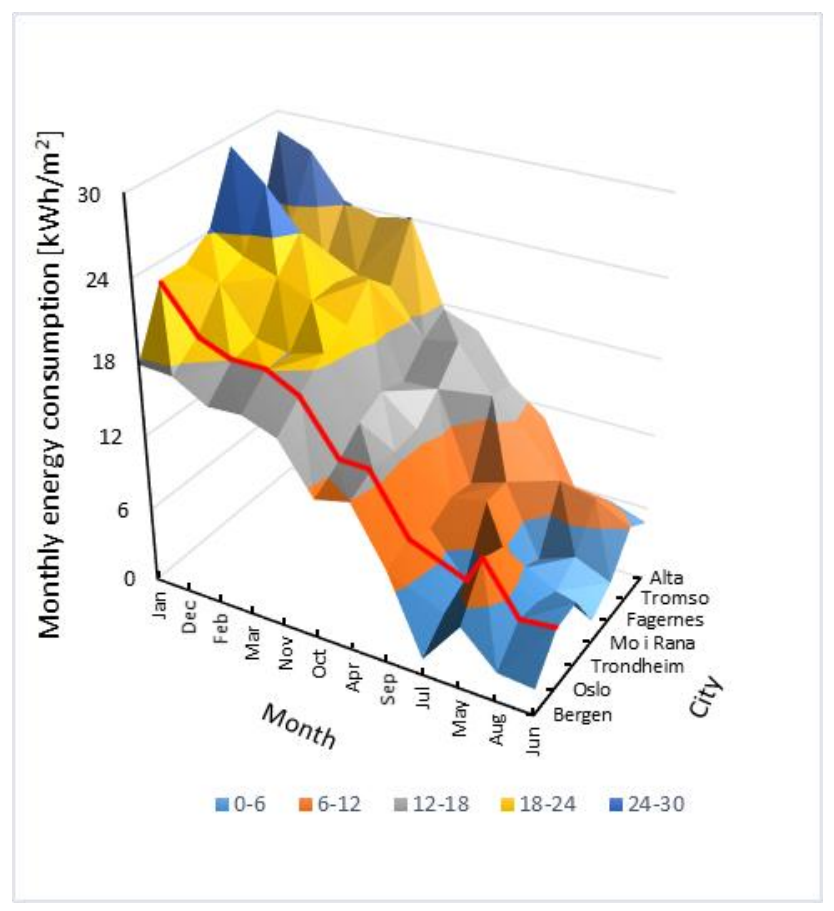

Figure 5. Monthly energy consumption in different Norwegian cities for the base case scenario in descending order.

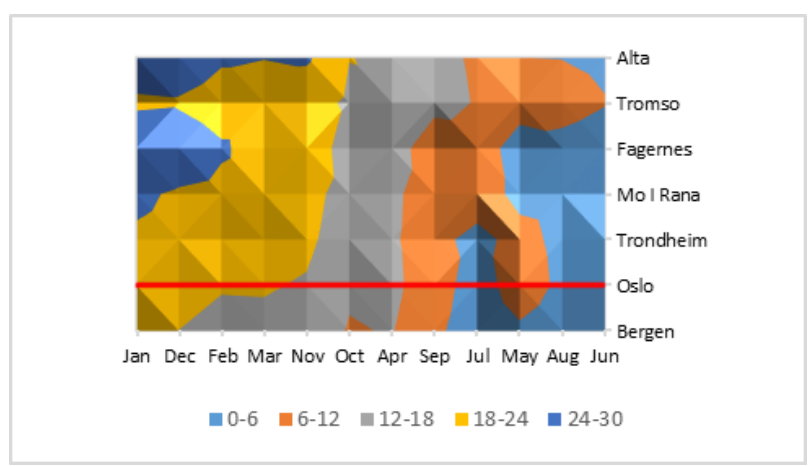

Figure 6. Monthly energy consumption in different Norwegian cities for the base case scenario in descending order-Front view.

The second round of simulation, with the improvements, is shown in Figure 7 and 8. It shows a more regular map, but the same trend as in the first round is visible. Bergen is the most unique zone, with the lowest energy demand, follow by Oslo and Trondheim with similar distribution of energy consumption through the months. Mo i Rana, 
Fagernes, Tromso and Alta is a third group, where the length of the heating periods is similar. Fagernes and Alta had the highest peak, incorporating an extra zone during January.

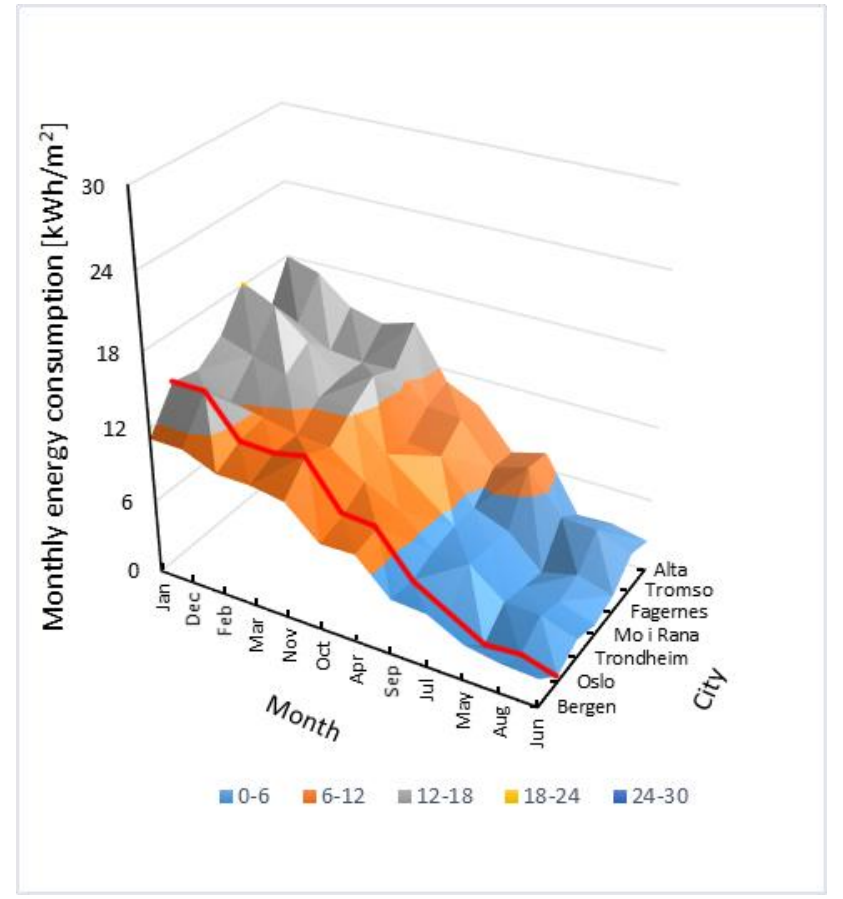

Figure 7. Monthly energy consumption in different Norwegian cities for the Norwegian passive house standard scenario in descending order.

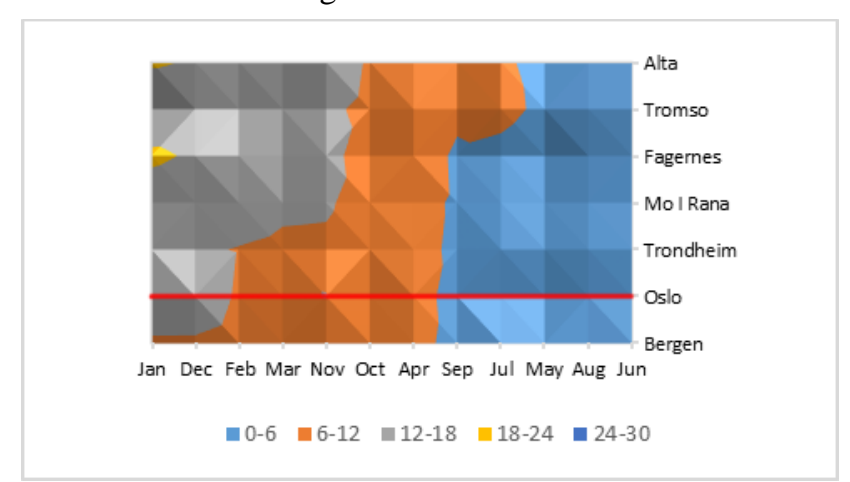

Figure 8. Monthly energy consumption in different Norwegian cities for the Norwegian passive house standard scenario in descending order-Front view.

\subsection{Energy labelling assessment}

An energy labelling simulation of the base case was performed with the Norwegian tool (and the standardized Norwegian weather file), which gave a D. The base case was also simulated with the IWEC and Meteonorm weather files. The results of the energy labelling simulations for each city are presented in Table 4 , and shows that the same label is achieved with both IWEC and Meteonorm weather data. However, the label for Oslo, Bergen and Trondheim was upgraded to a C, while the rest of the cities maintained the same labelling as achieved with the official Norwegian weather file. However, the steps for each letter from A to D is 38
$\mathrm{kWh} / \mathrm{m}^{2}$, the cities that had a score of $\mathrm{C}$ have an average improvement of $26 \mathrm{kWh} / \mathrm{m}^{2}$ from the D level, and these indicates that cities are not near the limit values between ranges, as can be seen in Figure 9.

Table 4. Labelling result for the base case.

\begin{tabular}{|l|l|l|l|}
\hline Climate Zone & $\begin{array}{l}\text { Official } \\
\text { Weather }\end{array}$ & IWEC & Meteonorm \\
\hline 1. Oslo & D & C & C \\
\hline 2. Bergen & D & C & C \\
\hline 3. Fagernes & D & D & D \\
\hline 4. Trondheim & D & C & C \\
\hline 5. Mo i Rana & D & & D \\
\hline 6. Tromso & D & D & D \\
\hline 7. Alta & D & D & D \\
\hline
\end{tabular}

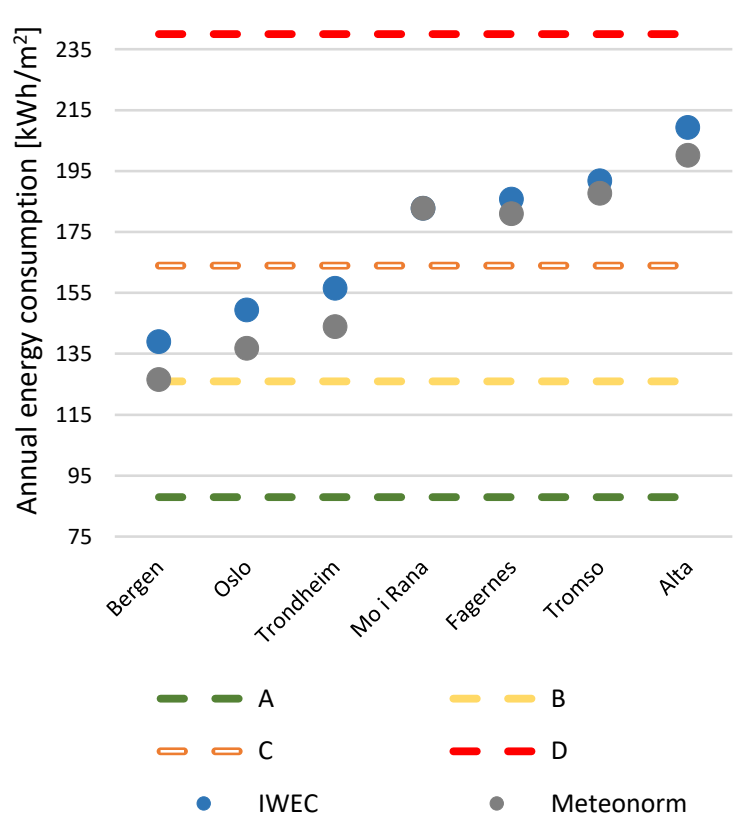

Figure 9. Results from the labelling under the bases cases scenario.

The scenario with the improvements (passive standard level) using the official Norwegian weather data file, gave the dwelling a $B$ level. The dwelling was only $4.32 \mathrm{kWh} / \mathrm{m}^{2}$ per year from an A, however, which is relatively close (the range of the $\mathrm{B}$ level is 38 $\mathrm{kWh} / \mathrm{m}^{2}$ ). The same case using IWEC weather data gave an $\mathrm{A}$ in Bergen and a $\mathrm{C}$ in Alta, while the rest of the cities reached a B. Alta was only $1 \mathrm{kWh} / \mathrm{m}^{2}$ per year from a B, though. The labels achieved by the Meteonorm weather data did not show the same concordance as the ones with IWEC data. This is because most of the results are close to the edge of the range of each letter. In despite of this, it is proved that 
by simulating the energy consumption of each city with local climate data they perform differently from Oslo.

Table 5. Labelling results for the passive house level.

\begin{tabular}{|l|l|l|l|}
\hline Climate Zone & $\begin{array}{l}\text { Official } \\
\text { Weather }\end{array}$ & IWEC & Meteonorm \\
\hline 1. Oslo & B & B & A \\
\hline 2. Bergen & B & A & A \\
\hline 3. Fagernes & B & B & B \\
\hline 4. Trondheim & B & B & A \\
\hline 5. Mo i Rana & B & B & B \\
\hline 6. Tromso & B & B & B \\
\hline 7. Alta & B & C & B \\
\hline
\end{tabular}

\subsection{Discussion}

Norway has a long tradition with energy performance regulations, and new buildings have already a high standard, one of the strictest in EU with this, housing envelope are prepared to efficiently isolate weather conditions. The good quality of the construction indicate that the main measures to reduce energy are not the properties of the envelope but the mechanical heating and ventilation systems. Nevertheless, the building envelope still play a role to reduce the energy losses. The results from this study clearly shows that the weather data file has an impact on the labelling, even if the building in question is on passive house level. These outcomes should be considered in the purposes of the certification system, since the aim of the labelling tools is to inform stakeholders about the performance of the property and with this enable them to compare different options. According to the presented results, however, this may not be the case under a single weather data file scheme. The study was conducted with a terraced dwelling, attached to adjacent dwellings on two sides. This leaves an exposed facade area of $82 \mathrm{~m}^{2}$, which represents $16 \%$ of the total envelope. This makes the energy demand of the dwelling less sensitive to weather than e.g. a detached dwelling. Thus, the study has a limitation in order to be representative for various kinds of dwellings. In this respect, future work should focus on proposing climate zones for labelling purposes in Norway, which can be used for policymaking as well as for improving energy saving estimations. In addition, overheating might be an issue in cold climates where buildings are built according to passive house standards. However, this was not confirmed in this study.

\section{Conclusion}

The analysis of the IWEC and Meteonorm weather data shows a correlation in energy consumption, which means that both can be used for energy labelling. Since IWEC represents real weather data, further analysis of the climate was performed. It became clear that the zone designation is somehow appropriate if the HDD are used as basis for the classification. However, if the energy consumption is used for the assessment of the zones, short steps can be seen between some zones, e.g. zone 5 (Mo i Rana) and 3 (Fagernes) with only 1\% difference, zone 6 (Tromso) and 3 (Fagernes) with $3 \%$ and zone 4 (Trondheim) and 1 (Oslo) with 4,5\%. Despite that this results might show that the zones can be merged, there is reason to think that cooling need might also influence, increasing the distance of the simulation results, but under a single zone approach this is hardly evident.

Labelling rating is the most important piece of evidence from the article to state that local weather data should be used, especially if renovation measures in order to target high level rating are considered. As it was mentioned before, the envelope insulation level is not the main source of energy reductions, however it plays an important role after the heating system is improved. The energy rating used in this study is mainly based on the envelope upgrade, following the Norwegian Passive standard. The conclusion from that task shows that in order to achieve a higher level of energy rating, different level of renovations should be considered according to climatic zone.

\section{References}

Al-Mofeez I. A., Numan M. Y., Alshaibani K. A., and Al-Maziad, F. A. Review of typical vs. synthesized energy modeling weather files. Journal of Renewable and Sustainable energy, 4(1), 2012.

Backhaus J., Tigchelaar, C., de Best-Waldhober and M. Key findings \& policy recommendations to improve effectiveness of Energy Performance Certificates \& the Energy Performance of Buildings Directive. Retrieved from, 2011.

Cappelletti F., Dalla Mora T., Peron F., Romagnoni P., and Ruggeri P. Building renovation: which kind of guidelines could be proposed for policy makers and professional owners? Energy Procedia, 78, 2366-2371, 2015.

Crawley D. B. Which weather data should you use for energy simulations of commercial buildings?/Discussion. Ashrae Transactions, 104, 1998.

Enova. Series of Bygningsnettverkets energistatistikk: 2002, 2003, 2004,2005, 2006. Retrieved from Trondheim, 2006.

Erba S., Causone F. and Armani R. The effect of weather datasets on building energy simulation outputs. Energy Procedia, 134, 545-554, 2017.

Fumo N. A review on the basics of building energy estimation. Renewable and Sustainable Energy Reviews, 31, 53-60, 2014.

Geissler S. and Altmann N. Certification. Overview and outcomes. In 2016-Implementing the Energy Performance of Buildings Directive (EPBD) - Featuring Country Reports. Concerted action EPBD, 2015.

Gherri B. Assessment of Daylight Performance in Buildings: Methods and Design Strategies: WIT Press. 2015.

Gillott M., Loveday D. L., White J., Wood C., Chmutina K. and Vadodaria K. Improving the airtightness in an existing UK dwelling: The challenges, the measures and their effectiveness. Building and Environment, 95, 227-239, 2016. 
Guan L. Preparation of future weather data to study the impact of climate change on buildings. Building and Environment, 44(4), 793-800, 2009.

Hensen, J. L. Simulation of building energy and indoor environmental quality-some weather data issues. Paper presented at the Proc. Int. Workshop on Climate data and their applications in engineering, 1999.

Herrera M., Natarajan S., Coley D. A., Kershaw T., RamalloGonzález A. P., Eames M. and Wood, M. A review of current and future weather data for building simulation. Building Services Engineering Research and Technology, 38(5), 602627, 2017.

Hinge A., Neely A. C. B. and Taylor C. Building energy rating schemes around the world: What do we know. Proceedings of the ACEEE, 2014.

Hong T., Chang W.-K. and Lin H.-W. A fresh look at weather impact on peak electricity demand and energy use of buildings using 30-year actual weather data. Applied Energy, 111, 333350, 2013.

Huang J. ASHRAE Research Project 1477-RP-Development of over 2,500 weather files for international locations. Final Report. ASHRAE, 2010.

Huang Y. J. Development of 3012 IWEC2 weather files for international locations (RP-1477). Ashrae Transactions, 120, 2014.

Hui S. C. and Cheung K. Climatic data for building energy design in Hong Kong and Mainland China. Proceedings. of the CIBSE National Conference 1997, 1997.

Institute for Market Transformation (IMT). A roadmap for creating building energy rating systems in central Asia, 2009.

International Energy Agency (IEA). Energy Performance Certification of Buildings: A policy tool to improve energy efficiency. Retrieved from https://www.iea.org/publications/freepublications/publication lbuildings_certification.pdf, 2010.

Lund $\mathrm{H}$. The design reference year. 3rd International IBPSA Conference, 1991.

Lund H. and Eidorff S. Selection Methods for Production of Test Reference Years: Final Report, Short Version: Commission of the European Communities, 1981.

Pernigotto G., Prada A., Cappelletti F. and Gasparella, A. Impact of Reference Years on the Outcome of Multi-Objective Optimization for Building Energy Refurbishment. Energies, 10(11), 2017.

Polly B., Kruis N. and Roberts D. Assessing and improving the accuracy of energy analysis for residential buildings. 2011.

Remund J., Müller S., Schilter C. and Rihm, B. The use of Meteonorm weather generator for climate change studies. 10th European Conference on Applications of Meteorology (ECAM) Abstracts, held Sept. 13-17, 2010 in Zürich, Switzerland. http://meetings. copernicus. org/ems2010/, id. EMS2010-417., 2010.

Roetzel A. and Tsangrassoulis A. Climate change sensitivity of comfort and energy performance criteria for offices. ANZAScA 2011: From principles to practice in architectural science: Proceedings of the 45th Annual conference of the Australian and New Zealand Architectural Science Association, 2011.

Sartori I., Wachenfeldt B. J. and Hestnes A. G. Energy demand in the Norwegian building stock: Scenarios on potential reduction. Energy Policy, 37(5), 1614-1627, 2009.
Tasktroup I. B. E. E. Building Energy Rating Schemes: Assessing Issues and Impacts. International Partnership for Energy Efficiency Cooperation, 2014.

Thevenard D. J. and Brunger A. P. The development of typical weather years for international locations: part I, algorithms. Ashrae Transactions, 108, 2002. 